\title{
PERILAKU SELF CARE MANAGEMENT PENDERITA HIPERTENSI: STUDI KUALITATIF
}

\author{
Salami Salami ${ }^{1}$ \\ ${ }^{1}$ Universitas 'Aisyiyah Bandung \\ salamisuyanto@gmail.com
}

\begin{abstract}
ABSTRAK
Hipertensi membutuhkan manajemen penyakit jangka panjang oleh penderitanya. Manajemen perawatan diri (self care management) ini berhubungan erat dengan perilaku penderita. Kegagalan melakukan self care akan berdampak terhadap terjadinya komplikasi yang mematikan. Penelitian ini bertujuan untuk mengeksplorasi perilaku self care manajement penderita hipertensi di Puskesmas Kota Bandung. Manfaat penelitian ini sebagai data dasar untuk petugas kesehatan dan pengambil kebijakan terkait perspektif pasien hipertensi dalam pengelolaan penyakitnya. Metode penelitian yang digunakan adalah deskriptif kualitatif. Partisipan pada penelitian berjumlah tujuh orang sesuai dengan kriteria inklusi dan eksklusi. Pemilihan partisipan dengan menggunakan Teknik Purposive Sampling. Pengumpulan data berdasarkan wawancara terstruktur menggunakan pedoman wawancara. Hasil wawancara dibuat verbatim. Data dianalisis dengan Model Miles Huberman. Untuk memenuhi prinsip keandalan data penelitian (Trustworthiness) dilakukan credibility, dependeability, confirmability, dan transferability. Hasil penelitian didapatkan tiga tema yaitu: pengobatan yang dilakukan, upaya self care management, dan persepsi terhadap penyakit. Petugas kesehatan disarankan untuk memberikan intervensi yang tepat pada penderita hipertensi terkait persepsi penyakit, terutama tentang efek samping pengobatan. Dengan ersepsi yang tepat diharapkan penderita menjadi lebih patuh minum obat
\end{abstract}

Kata kunci : hipertensi, self care management, studi kualitatif

\section{THE BEHAVIOR OF SELF CARE MANAGEMENT HYPERTENSION PATIENTS: QUALITATIVE STUDY}

\begin{abstract}
Hypertension requires long-term disease management. Self-care management is closely related to the behavior of the patients. The lack of success in self-care will impact the occurrence of deadly complications. This study explores the behavior of self-care management of hypertension sufferers at the Bandung City Health Center. The advantage of this research is primary data for health workers and policymakers regarding the perspective of hypertensive patients in managing their disease. The research method used is the descriptive qualitative method. Hypertensive patients that included in the study according to the inclusion criteria. Furthermore, exclusion were seven participants. Participant selection using the purposive sampling technique. Data collection based on structured interviews using interview guidelines made verbatim. The data were analyzed using the Miles Huberman model. Reliability of research data done by meeting the principles of credibility, dependability, confirmability, transferability. Three themes are treatment, efforts, and constraints on self-care management and perception of the disease. Therefore, it recommended providing appropriate interventions for hypertensive patients related to disease perception, self-care management, and treatment adherence, especially about misperceptions related to side effects of treatment so that patients are
\end{abstract}


obedient to taking medication.

Keywords: hypertension, qualitative study, self-care management

\section{PENDAHULUAN}

Hipertensi atau tekanan darah tinggi dikenal sebagai the silent killer, karena seringkali penderitanya tidak merasakan gejala sampai terjadinya komplikasi yang berbahaya. Hal ini menyebabkan angka mortalitas penyakit ini tinggi akibat komplikasi yang menyertainya. Padahal hipertensi adalah penyakit yang mudah didiagnosis dan telah tersedia beberapa pengobatan yang memadai, baik pengobatan secara nonfarmakologis maupun farmakologis. Meskipun pengobatan hipertensi terbukti efektif tetapi angka kepatuhan penderita hipertensi terhadap pengobatan masih rendah. Diperkirakan hanya satu orang dari lima orang penderita hipertensi yang mengontrol penyakitnya. (World Health Day, 2013)

Sebagaimana penyakit kronis umumnya, hipertensi membutuhkan manajemen penyakit jangka panjang seumur hidup penderitanya. Disamping penderita, pengelolaan penyakit ini juga membutuhkan keterlibatan keluarga dan petugas kesehatan. Manajemen perawatan hipertensi pada dasarnya berhubungan erat dengan perilaku penderita. Komponen penting dalam manajemen perawatan ini meliputi: kepatuhan pengobatan, pemantauan tekanan darah sendiri, dan modifikasi gaya hidup seperti diet, olahraga, dan pengurangan tembakau telah terbukti memberikan perbaikan yang signifikan dalam mengontrol hipertensi dan berhubungan juga dengan kualitas hidup (Bairami, Fathi, Mohammadinasab, Barati, \& Mohammadi, 2017)

Dalam upaya pengelolaan hipertensi, pemerintah telah melakukan berbagai program diantaranya adalah dengan membentuk Posbindu PTM ( Pos pembinaan terpadu penyakit tidak menular) sebagai bentuk partisipasi masyarakat, menyelenggarakan program pengendalian penyakit kronis (Prolanis) bekerjasama dengan BPJS Kesehatan. Prolanis mencakup dua program penyakit kronis yang sangat penting di Indonesia yaitu diabetes dan hipertensi. Selain hal tersebut, upaya lain yang dilakukan adalah dengan menjadikan hipertensi sebagai salah satu indikator dalam Program Indonesia Sehat dengan pendekatan Keluarga (PIS-PK). Program ini dilakukan melalui kegiatan kunjungan rumah, pendataan, entri dan analisis data sehingga alternatif penyelesaian masalah kesehatan berbasis data yang tepat. Pada pertengahan tahun 2018 pelaksanaan PIS-PK di sebagian besar Puskesmas di Indonesia baru mencapai tahapan kunjungan rumah (Laelasari et al., 2019)

Meskipun pemerintah telah melakukan upaya-upaya strategis dalam pengelolaan hipertensi, tetapi kunci penting pengelolaan penyakit tetaplah penderita itu sendiri. Penderita harus dilibatkan dalam perawatan mandiri penyakitnya atau yang dikenal dengan self care karena penderita adalah pelaku utama yang akan melakukan semua pengobatan dan juga melakukan aktivitas-aktivitas yang menunjang keberhasilan perawatan penyakitnya.

Dalam konteks pengelolaan/ perawatan mandiri hipertensi, American Heart Association (AHA) merekomendasikan modifikasi perilaku yang berkaitan dengan self care yang terdiri atas: diet rendah garam, diet sehat, melakukan aktifitas fisik, mengurangi merokok, dan alkohol, menurunkan stres, menurunkan papaparan polusi, dan paparan udara dingin. (Unger et al., 2020)

Tetapi sayangnya tidak semua penderita mampu melakukan manajemen pengelolaan penyakit dengan baik. Di Indonesia menurut hasil penelitian berdasarkan data yang dianalisis dari Indonesia Family Life Survey (IFLS5) menunjukkan bahwa prevalensi penderita 
hipertensi tinggi, tetapi tingkat kesadaran akan penyakit hanya $42,9 \%$, dari angka tersebut yang melakukan pengobatan hanya $11,5 \%$ dan yang mengontrol penyakitnya hanya 14,3\% (Peltzer \& Pengpid, 2018)

Merujuk data tersebut, semakin memperkuat fenomena bahwa keberhasilan pengelolaan hipertensi di Indonesia masih kurang dan membutuhkan upaya serius berbagai pihak. Self care menjadi langkah yang penting untuk dilakukan sebagai bagian tidak terpisahkan dalam manajemen kasus hipertensi. Buruknya self care management hipertensi berkorelasi dengan meningkatnya angka komplikasi penyakit. Berdasarkan data dari Dinas Kesehatan Kota Bandung merujuk pada kajian tentang penyakit tidak menular pada tahun 2016, dilaporkan bahwa jumlah kematian maupun penyakit terbanyak di Kota Bandung disebabkan oleh penyakit tidak menular. Dengan angka penyakit strok sebesar $8,24 \%$, penyakit kardiovaskular $13,73 \%$, dan penyakit diabetes mellitus mencapai 3,15\%. (Diskominfo - PPID, 2017). Kondisi ini tentu merupakan tantangan bagi sistem kesehatan berkaitan dengan penanganan hipertensi sehingga kemampuan penderita dalam melakukan pengelolaan penyakitnya atau self care management perlu dikaji agar intervensi kesehatan yang diberikan adekuat sesuai dengan kebutuhan penderitanya.

Oleh karena itu, pengetahuan yang lebih baik tentang pengelolaan hipertensi dan bagaimana perilaku penderitanya, menjadi penting untuk dipahami. Pemahaman ini diharapkan akan dapat membantu penyesuaian intervensi kesehatan atau program peningkatan pengelolaan penyakit hipertensi supaya lebih tepat.

Penelitian ini bertujuan untuk mengetahui secara lebih mendalam perilaku self care management penderita hipertensi dalam mengelola penyakitnya. Penelitian ini diharapkan menjadi data dasar petugas puskesmas dan pengambil kebijakan untuk memberikan intervensi kesehatan sesuai dengan kebutuhan penderita.

\section{METODOLOGI}

Penelitian ini adalah deskriptif kualitatif. Teknik pengumpulan berupa wawancara terstruktur terhadap tujuh partisipan penderita hipertensi di Puskesmas Kota Bandung pada tanggal 20 Juni sampai dengan 19 Agustus 2018. Pengambilan partisipan dengan metode purposive sampling. Teknik wawancara menggunakan pedoman berupa wawancara yang penulis susun mengacu Self Care Management Behaviour.

Wawancara dilakukan oleh peneliti sendiri dengan menggunakan hand phone dan menuliskan ekspresi pasien pada buku catatan. Wawancara dilakukan sebanyak 2-3 kali dengan waktu rata-rata 45-60 menit. Wawancara berlangsung di rumah partisipan dan di tempat lain yang sudah disepakati. Sebelum melakukan wawancara peneliti mengatur waktu dan tempat wawancara sesuai kesepakatan dengan partisipan. Pedoman wawancara yang berisikan aspek-aspek tentang pengelolaan penyakit. Pertanyaan yang diajukan adalah perilaku self care management yang meliputi pengobatan, diet kadar garam, keteraturan berolahraga, pengendalian berat badan dan pengurangan merokok dan meminum alkohol Seluruh partisipan mengisi inform consent sebelum wawancara dilakukan.

Hasil wawancara didengarkan berulangulang, ditulis dan dibuat verbatim/ transkripsi. Teknik analisis dalam penelitian ini menggunakan Analysis Interactive Model Miles dan Huberman. Pada bagian memfokuskan data dengan cara menyeleksi data yang sesuai dengan tujuan penelitian. dan memfokuskan data. Selanjutnya data tersebut disusun berdasarka kategori agar mudah dipahami. Langkah terakhir adalah 
menarik kesimpulan dalam bentuk tema. Untuk keandalan data penelitian (Trustworthiness) dalam penelitian ini, peneliti mengaplikasikan prinsip credibility, dependeability, confirmability, dan transferability. Validasi data ulang kepada ulang kepada partisipan terkait tema yang peneliti lakukan. Dan juga menggunakan sumber eksternal yaitu dosen yang berpengalaman dalam penelitian kualitatif.

\section{HASIL}

Tabel 1. Data Demografi Partisipan

\begin{tabular}{lllllll}
\hline $\begin{array}{l}\text { No. } \\
\text { Partisipan }\end{array}$ & $\begin{array}{l}\text { Jenis } \\
\text { Kelamin }\end{array}$ & $\begin{array}{l}\text { Umur } / \\
\text { tahun }\end{array}$ & Pendidikan & $\begin{array}{l}\text { Suku } \\
\text { Bangsa }\end{array}$ & Pekerjaan & $\begin{array}{l}\text { Lama } \\
\text { Menderita } \\
\text { Hipertensi }\end{array}$ \\
\hline P1 & P & 34 & D3 & Sunda & IRT & 2 tahun \\
P2 & P & 65 & SMA & Sunda & IRT & 5 tahun \\
P3 & P & 54 & SMP & Sunda & Pensiunan & 10 tahun \\
P4 & P & 56 & D3 & Jawa & IRT & 3 tahun \\
P5 & L & 43 & D1 & Sunda & Wiraswasta & 4 tahun \\
P6 & L & 57 & SMA & Jawa & Pensiunan & 6 tahun \\
P7 & L & 70 & S1 & Jawa & Pensiunan & 12 tahun \\
\hline
\end{tabular}

Jumlah partisipan penelitian sebanyak 7 orang. Partisipan berusia pada kisaran antara 34 tahun sampai dengan 70 tahun, Berdasarkan Pendidikan partisipan 1 orang SMP, 2 orang SLTA, 1 orang D1, 2 orang D3 dan 1 orang S1. Pekerjaan partisipan bervariasi, 3 orang tidak bekerja/ Ibu RT, 3 orang pensiunan, 1 orang lainnya adalah wiraswasta.. 4 orang Partisipan bersuku Sunda dan tiga orang bersuku Jawa. Partisipan penelitian ini empat orang perempuan dan tiga orang laki-laki. Lama menderita hipertensi antara tiga tahun sampai dua belas tahun.

\section{Hasil Analisis Tema}

Berdasarkan hasil wawancara.ditemukan tiga tema. yaitu kepatuhan dan pengobatan yang dilakukan, upaya self care management dan persepsi terhadap penyakit. Tema-tema tersebut tersusun atas beberapa sub tema yang dibangun dari beberapa kategori seperti terlihat dalam tabel analisis tematik di bawah ini.

Tabel 2. Analisis tematik

\begin{tabular}{|c|c|c|}
\hline Kategori & Subtema & Tema \\
\hline $\begin{array}{ll}\text { - } & \text { Obat dari dokter } \\
\text { - } & \text { Obat dari warung } \\
\text { - } & \text { Pengobatan alternatif } \\
\text { - } & \text { Pengobatan herbal } \\
\text { - } & \text { Apabila ada gejala } \\
\text { - } & \text { Rutin }\end{array}$ & $\begin{array}{ll}\text { - } & \text { Jenis pengobatan } \\
\text { - } & \text { Manfaat pengobatan } \\
\text { - } & \text { Keteraturan minum obat }\end{array}$ & $\begin{array}{l}\text { Kepatuhan dan Pengobatan yang } \\
\text { dilakukan }\end{array}$ \\
\hline
\end{tabular}




\begin{tabular}{|c|c|c|}
\hline Kategori & Subtema & Tema \\
\hline $\begin{array}{ll}\text { - } & \text { Mengurangi makanan asin } \\
\text { - } & \text { mengurangi instan } \\
\text { - } & \text { Masih ngemil } \\
\text { - } & \text { Tidak pilih-pilih makanan } \\
\text { - } & \text { Terkendidak teratur } \\
\end{array}$ & Modifikasi Diet & \\
\hline $\begin{array}{ll}\text { - } & \text { Jalan kaki } \\
\text { - } & \text { Tidak pernah olahraga } \\
\text { - } & \text { Senam jantung } \\
\text { - } & \text { Kerja sehari-hari } \\
\end{array}$ & Olahraga & Upaya self care management \\
\hline $\begin{array}{ll}\text { - } & \text { Piknik } \\
\text { - } & \text { Ngobrol } \\
\text { - } & \text { Makan-makan } \\
\text { - } & \text { Shopping } \\
\text { - } & \text { Banyak ngaji } \\
\text { - } & \text { Banyak shalat }\end{array}$ & Mengelola stress & \\
\hline
\end{tabular}

- Cek tekanan darah di posbindu, cek sekalian prolanis-puskesmas Kontrol tekanan darah

- Cek pake digital

- Kontrol ke dokter praktik

- Keturunan

- Makanan yang asin

- Sering emosi Persepsi terhadap faktor

- Kegemukan

- Bisa stroke, gagal ginjal

- Sakit kepala

- Kemana-mana dampaknya penyebab

- Susah sembuh

- Dapat sembuh asal rajin Persepsi terhadap kesembuhan berobat

1. Kepatuhan dan Pengobatan yang Dilakukan

Berdasarkan hasil wawancara didapatkan data mayoritas partisipan menggunakan pengobatan medis dalam pengelolaan penyakitnya, empat orang menyatakan rutin meminum obat dan tiga orang tidak rutin atau apabila gejala muncul saja. Disamping menggunakan obat medis, rata-rata partisipan juga menggunakan pengobatan alternatif seperti bekam dan akupuntur seperti diungkapkan oleh beberapa partisipan berikut ini.

\subsection{Pengobatan Medis}

"Minum obat amlodipin dari dokter $H$, minum satu pagi-pagi setelah sarapan,. tapi kalo lagi kerasa aja" (P-1)

"Kalo pusing, saya minum panadol dulu...kalo masih kerasa baru ke dokter" (P-2)

"Ibu tidak terus terusan minum obat, soalnya Ibu pernah setelah minum obat 
perutnya jadi gak enak, obat kan kimia berbahaya juga" (P-3)

"Kadang -kadang minum obat kadangkadang tidak, soalnya bapak sering lupa juga hehehe" (P-5)

"Saya selalu kontrol, dikasih obat buat satu bulan rutin diminum ..." (P-7)

\subsection{Pengobatan Alternatif dan Herbal}

"Ibu dibekam sebulan sekali ....kalo sudah dibekam badan jadi terasa enteng “(P-3)

"Disamping obat dokter...juga ke alternative... terapi akupuntur, kerasa berkurang juga pusing... "( $\mathrm{P}-4)$

"Bapa ikut terapi, tiap hari ke sana... tidur-tiduran di matras kerasanya enak aja, ke badan...gak kaku..”(P-6)

"Selain berobat rutin, sejak bulan September saya juga rutin minum minyak zaitun .. herbal, ,saya berencana berhenti minum obat karena khawatir efeknya ke ginjal." (P-7)

\section{Upaya Self Care management}

\subsection{Modifikasi Diet}

Tema kedua yang teridentifikasi yaitu Upaya dan Hambatan self care management .Tema ini dibangun oleh beberapa sub tema seperti, modifikasi diet yang dilakukan. Kegiatan olahraga, cara mengelola stress dan mengontrol tekanan darah. Berikut ungkapan beberapa partisipan terkait modifikasi diet:

"Suka ngemil keripik -keripik, padahal gak boleh...tapi suka ada yang ngasih"
"Sudah mengurangi makan yang asin, tetapi masih sering makan kerupuk hehehe" (P-2)

"Kalo masak biasanya dikurangi garamnya......." (P-4)

"Dietnya belum teratur, tidak enak kalo sayurnya kurang garam gak kerasa apaapa..." (P-5)

"Makanan juga kan nikmat dari Alloh jadi harus disyukuri jangan pilih-pilih... Bapak kalo lagi pingin ikan asin ya makan saja hehe" (P-6)

"Kadang-kadang ditabrak juga...jadi misalnya pengen makan asin ya... makan saja... kan tidak setiap hari juga" $(P-7)$

"Biasanya kalo ke undangan atau ada acara gitu, susah batasin makan ya makan aja yang ada, ........ susah nyegahnya hehee." (P-3)

\subsection{Olah Raga yang Dilakukan}

Berdasarkan

wawancara menunjukkan bahwa beberapa partisipan melakukan olah raga. Meskipun tidak rutin tapi ada beberapa partisipan yang melakukan olahraga sesuai dengan kemampuannya Seperti ungkapan partisipan berikut ini:

"Jalan kaki pagi-pagi ......itupun kalo lagi gak males" (P-1)

" bu jarang olahraga, karena cepet cape (P-2)

"Kadang-kadang ikut senam jantung di lapang Lodaya." (P-3) 
"Setiap hari kecuali Senin Kamis, jalan keliling 4 kali kira-kira satu jam-lah... kalo cape berhenti terus jalan lagi..”(P-5)

"Jarang olahraga, kan di rumah juga Bapa mah banyak kegiatan banyak bergerak(P6)

“ .....ikut senam tiap Jumat di puskesmas........... (P-7)

\subsection{Mengelola Stres}

Para partisipan dalam penelitian ini melakukan berbagai upaya dalam mengelola stress seperti piknik, ngobrol, makan-makan, shopping. Dalam penelitian ini beberapa partisipan dalam mengelola stresnya melakukan hal-hal positif dengan cara mendekatkan diri pada Tuhan yaitu mengikuti pengajian dan memperbanyak shalat. Seperti diungkapkan partisipan berikut ini:

"Biar gak stress, saya juga shopping ke mall kadang-kadang cuman liat-lihat aja” $(P-1)$

"Kadang-kadang piknik bareng tementemen kompleks “(P-2)

"Ibu mah ikutan pengajian,...banyakin ngaji ..supaya adem gak banyak emosi ." (P-3)

"Banyakin shalat termasuk yang sunah... tahajud. Bapa sering berdoa biar bisa sembuh dan gak kena stroke" (P-6)

"Kalo lagi banyak pikiran, ke rumah anak, ngobrol sama cucu” (P-7)

\subsection{Kontrol tekanan darah}

Perilaku self care management lainnya yang dilakukan oleh partisipan adalah mengontrol tekanan darah.
Ungkapan partisipan yang menunjang subtema ini tampak seperti di bawah ini:

"Ngak tentu, kadang sebulan, tiga bulan... baru periksa kalo kerasa sakit aja $(P-1)$

"Kadang- kadang cek tekanan ke posbindu” (P-2)

"Ngecek tensinya kalo ada pusing Ibu punya tensi digital" (P-3)

"Kalo Ibu periksanya ke puskesmas periksa tensi dan sekalian dikasih obat" $(P-4)$

"Saya kontrol sebulan sekali, sekalian ikut prolanis, saya juga sedang target menurunkan tensi biar stabil" (P-7)

\section{Persepsi Terhadap Penyakit}

Berdasarkan hasil wawancara tema ketiga ini dibangun oleh beberapa sub tema yaitu persepsi terhadap sakit, persepsi terhadap pengobatan dan persepsi terhadap dampak penyakit. Uraian ungkapan partisipan seperti terlihat berikut ini

\subsection{Persepsi terhadap penyebab sakit}

Partisipan memiliki persepsi yang berbeda-beda terhadap penyakitnya ada yang menyatakan bahwa sakit hipertensi yang diderita karena faktor keturunan, ada juga yang karena senang makan yang asin-asin, sering emosi dan kegemukan. Pernyataan penting partisipan terkait tema dapat dibaca pada ungkapan berikut ini:

"Mungkin keturunan, Ibu saya punya darah tinggi dan kena stroke” (P-1)

"Di keluarga gak ada yang darah tinggi mungkin karena saya suka yang asin- 
asin sejak gadis (P-2)”

"Memang Ibu bawaannya pingin marah terus...kan kata orang juga kalo sering marah-marah jadi darahnya naek hehehe" (P-3)

"Kalo saya kata dokter kegemukan sepertinya dari situ makanya tekanan nya suka tinggi” (P-5, P-7)

\subsection{Persepsi Terhadap Dampak}

Dalam hal pengobatan partisipan mempunyai persepsi bahwa bisa stroke, gagal ginjal, sakit kepala, kemana-mana dampaknya. Berikut ungkapan partisipan:

"Paling bahaya.. bisa stroke" (P-1, P-2, $P-3, P-4)$

"Dampak yang paling kerasa sakit kepala" (P-5,P-6)

"Penyakit ini dampaknya kan kemanamana, bisa ke jantung, ke ginjal, mata, stroke" (P-7)

\subsection{Persepsi terhadap kesembuhan}

Subtema ini dibangun oleh beberapa kategori susah sembuh, dapat sembuh asal rajin berobat dan menjaga makanan, olahraga dan menjauhi stres.

"Kata dokter, penyakit ini ga bisa sembuh tapi bisa dikontrol” (P-1, P-3)

"Bisa sembuh, asal disiplin minum obat" $(P-5)$

"Gak bisa disembuhkan tapi kalo kita jaga makanan, olahraga jauhi stress tensinya jadi stabil” (P-6)

"Susah sembuh, apabila kalo banyak pikiran namanya juga hidup pasti banyak masalah" (P-4, P7)

\section{PEMBAHASAN}

\section{Kepatuhan dan Pengobatan yang dilakukan}

Tema pertama dalam penelitian ini yaitu tentang kepatuhan dan pengobatan yang dilakukan. Tema ini merupakan perilaku penting dalam mengelola penyakit hipertensi yang diderita. .. Hasil penelitian menunjukan bahwa sebagian partisipan meminum obat dari dokter dan satu orang meminum obat herbal. Beberapa partisipan lainnya mengkombinasikan pengobatan medis dengan pengobatan alternatif hal ini dilakukan karena partisipan merasakan manfaat seperti pusing berkuang atau badan jadi tidak kaku.

Untuk pengobatan medis tidak semua partisipan patuh terhadap pengobatan karena ada partisipan yang mengkonsumsi obat tidak rutin atau hanya ketika ada gejala saja. Ada juga partisipan yang minum obat warung terlebih dahulu ketika gejala hipertensinya muncul. Hasil penelitian ini sejalan dengan hasil Riset kesehatan Dasar tahun 2018 yang menyatakan bahwa ada berbagai alasan penderita hipertensi tidak minum obat yaitu penderita hipertensi merasa sehat $(59,8 \%)$, kunjungan tidak teratur ke fasilitas kesehatn $(31,3 \%)$, minum obat tradisional $(14,5 \%)$, terapi lain $(12,5 \%)$, lupa minum obat (11,5\%), tidak mampu membeli obat $(8,1 \%)$, takut efek samping $(4,5 \%)$, dan tidak tersedia obat hipertensi di fasilitas kesehatan $(2 \%)$. Alasan terbesar dalam kepatuhan minum obat oleh penderita adalah penderita merasa sehat kemungkinan berkaitan dengan tingkat pengontrolan penyakit yang rendah.(Kemenkes RI, 2019)

Penelitian ini juga sejalan dengan penelitian sebelumnya di Malaysia yang melaporkan bahwa kepatuhan dalam pengobatan masih terjadi yang dikarenakan oleh faktor lupa minum obat. Lebih jauh sebuah review tentang kepatuhan pengobatan sebagaimana dikutip 
oleh Ashoorkhani, et.al (2018) menemukan fakta bahwa disamping itu faktor lupa, faktor lainnya adalah banyaknya penderita hipertensi yang ketakutan akan efek samping obat. Karena obat ini harus diminum terus menerus sepanjang hidup penderitanya demikian juga ada anggapan ketika gejala penyakitnya tidak muncul berarti obat tidak perlu diminum. (Ashoorkhani, Majdzadeh, Gholami, Eftekhar, \& Bozorgi, 2018)

Ketidakpatuhan terhadap pengobatan merupakan faktor pendorong utama terjadinya kenaikan tekanan darah pada penderita hipertensi dan merupakan indikasi prognosis yang buruk. Ketidakpatuhan ini berkolerasi signifikan terhadap terjadinya komplikasi penyakit yang membahayakan.(Unger et al., 2020) Beberapa penelitian mengungkapkan bahwa banyak penyebab seorang penderita tidak patuh terhadap pengobatan juga berkaitan dengan persepsi yang salah tentang dampak buruk obat hipertensi bagi kesehatan seperti diungkapkan oleh partisipan dalam penelitian ketakutan efek samping ke ginjal sehingga berencana berhenti minum obat dari dokter.

Di samping hal tersebut faktor lainnya berhubungan dengan efikasi diri penderita hipertensi hal pengobatan. Peran petugas kesehatan dalam hal kepatuhan berobat yang penting adalah upaya meningkatkan efikasi diri penderita dan pemberian pendidikan kesehatan yang tersturuktur. Intervensi ini telah terbukti memiliki makna bagi penderita hipertensi pada lansia. Mengacu pada hasil penelitian yang menunjukan bahwa penggunaan pengobatan herbatan dan terapi alternative juga digunakan pleh partisipan maka hal tersebut dapat dijadikan materi dalam pendidikan kesehatan supaya penderita hipertensi terhindar dari pemakainan obat-obatan dan terapi alternatif yang tidak aman (Khomaini, Setiati, Lydia, \& Dewiasty, 2017; Salami \& Wilandika, 2018)

\section{Upaya Self Care Management}

Tema kedua yang ditemukan dalam penelitian ini adalah Upaya self care management. Tema ini berhubungan erat dengan perilaku penderita hipertensi dalam mengelola penyakitnya. JNC 8 terapi farmakologi dan non farmakologi dalam management paseien hipertensi. Untuk melakukan rekomendasi tersebut dibutuhkan keterlibatan penderita, sebagai kunci utama pengelolaan penyakit. Seperti penyakit kronis lainnya, hipertensi memerlukan pengobatan dan perawatan yang lama bahkan seumur hidup penderitanya. Penderita harus mampu melakukan modifikasi gaya hidup sehat agar tujuan pengobatan dan perawatan menjadi optimal. (Unger et al., 2020)

Hasil penelitian ini menunjukkan ada empat komponen perilaku self care management yang ditemukan pada partisipan yaitu modifikasi diet, olahraga, mengelola stress dan kontrol tekanan darah. Ke empat komponen tersebut akan diuraikan satu persatu dalam pembahasan ini. Dalam modifikasi diet, ditemukan fakta bahwa sebagian partisipan belum mampu melakukannya dengan baik. Hal ini dapat terlihat dari ungkapan-ungkapan masih makan yang asin-asin, makan apa saja yang dimaui. Padahal diet rendah garam bagi penderita hipertensi sangat diperlukan. Karena konsumsi garam berlebih pada penderita hipertensi dapat meningkatkan jumlah natrium dalam sel. Karena salah satu fungsi natrium adalah mengikat air, keadaan ini dapat mengganggu keseimbangan cairan. Akibatnya cairan akan masuk ke dalam sel sehingga akan terjadi pengecilan diameter pembuluh darah arteri sebagai dampaknya jantung harus memompa darah lebih kuat. Kondisi ini yang mengakibatkan meningkatnya tekanan darah penderita(John Edward Hall, 2014)

WHO merekomendasikan bahwa konsumsi garam untuk orang sehat tidak boleh 
lebih dari 5 gr atau 1 sendok makan teh per hari. Konsumsi garam di Indonesia menurut data Survei Konsumsi Makanan Individu (SKMI) tahun 2014 konsumsi garam $>5 \mathrm{~g} /$ hari, yaitu $(6,68 \pm 5,85) \mathrm{g} / \mathrm{hari}$. Pada orang dengan hipertensi penurunan konsumsi garam sebanyak 4,4 g/hari selama setidaknya 4 minggu diketahui dapat menurunkan tekanan darah sistolik sebanyak $4 \mathrm{mmHg}$, sedangkan penurunan tekanan darah diastolik sebesar $2 \mathrm{mmHg}$. (He, Li, \& Macgregor, 2013)

Konsumsi garam penderita hipertensi disarankan tidak lebih dari $1.500 \mathrm{mg}$ per hari. Dan untuk Jika ingin kesehatan jantung dan pembuluh darah sebaiknya membatasi konsumsi garam menjadi $1.000 \mathrm{mg}$ per hari (Atmarita, Jahari, Sudikno, \& Soekatri, 2017; World Health Organization, 2017a)

Self care management lainnya yang ditemukan pada penelitian ini adalah olahraga. Jenis olahraga yang dilakukan adalah aerobik yaitu aktivitas olahraga dengan intensitas rendah hingga sedang yang dilakukan secara terusmenerus. Jalan kaki dan senam jantung adalah jenis olahraga yang dipilih oleh partisipan. Dari penelitian ini juga diketahui bahwa tidak semua partisipan berolahraga alasan yang dikemukakan adalah karena capai dan menganggap bahwa banyak kegiatan di rumah adalah sebagai olahraga. Pentingnya olahraga bagi kesehatan sudah banyak diteliti, dan banyak bukti yang menyatakan bahwa olahraga memberikan manfaat yang banyak bagi tubuh kita. Secara fisiologi, olahraga akan meningkatkan kerja dan fungsi jantung melalui mekanisme vasodilatasi pada sistem kardiovaskuler yang ditandai dengan penurunan denyut nadi, meningkatkan tonus parasimpatis serta memperkuat toleransi terhadap iskemia dan cedera.

Pada pasien hipertensi olahraga diketahui sebagai salah satu pengobatan non farmakologi. Merujuk pada data WH0, diketahui bahwa aktivitas olahraga berpengaruh dalam penurunan tekanan darah sebesar tekanan darah sistolik sebesar 7,4 mmHg dan tekanan diastolik sebesar 5,8 mmHg. serta menurunkan resiko strok sebesar 35-40\% dan resiko penyakit kardiovaskular sebesar 20-25\%. . Olahraga berbeda dengan aktivitas pekerjaan rumah. Karena olahraga harus mencakup jenis, tata cara dan durasi latihan. Pada penderita hipertensi dianjurkan untuk olahraga ringan dan rutin minimal 3-5 kali seminggu dengan intensitas kurang lebih 30 menit.dapat memberikan manfaat tetapi harus juga diimbangi dengan aktivitas yang cukup atau tidak low activity. (World Health Organization, 2017b)

Temuan lainnya pada tema Upaya Self Care Management adalah adalah upaya mengelola stress. Partisipan pada penelitian ini sudah mampu mengelola stress dengan baik yang ditunjukkan dengan mekanisme koping yang adaptif misalnya dengan memperbanyak ibadah atau mengobrol, makan, piknik atau shopping. Secara definisi stress adalah persepsi terhadap tuntutan yang diyakini melebihi sumber daya seseorang untuk beradaptasi dengan situasi. Secara fisiologis, stress yang berkepanjangan dapat dikaitkan dengan hipertensi. Stress berpengaruh terhadap peningkatan saraf simpatis menyebabkan pelepasan katekolamin sehingga akan terjadi peningkatan denyut jantung, curah jantung, dan tekanan darah.

Untuk menyelesaikan stress yang dirasakan, beberapa partisipan dalam penelitian ini telah berusaha mengelola stress dengan mekanisme strategi koping yang berfokus pada emosi (emotion focused coping) karena usahausaha penyelesaian masalah hanya bersifat memodikasi emosi saja.(Maryam, 2017). Perilaku self care management lainnya yang dilakukan oleh partisipan adalah mengontrol tekanan darah.Pentingnya mengontrol tekanan darah telah sebagian partisipan dalam penelitian ini. 
Manfaat mengontrol tekanan darah yang teratur berhubungan dengan kecepatan melakukan intervensi apabila tekanan darah naik. Meskipun demikian, Tucker et.al dalam penelitiannya menyatakan bahwa terkait langsung dengan tekanan darah yang lebih rendah atau kontrol yang lebih baik sehingga tetap disertai harus disertai dengan intervensi yang tepat untuk penurunan tekanan darah. (Tucker et al., 2017)

\section{Persepsi Terhadap Penyakit}

Tema ketiga dalam penelitian ini adalah persepsi terhadap penyakit. Tema ini dibangun dari tiga sub tema yaitu Persepsi terhadap penyebab penyakit, persepsi terhadap dampak dan persepsi terhadap kesembuhan. Persepsi penyakit didefinisikan sebagai interpretasi penderita terhadap penyakitnya. Sebagian besar partisipan memiliki pemahaman yang benar tentang penyakit.nya.

$$
\text { Banyak faktor yang }
$$

mempengaruhi persepsi penyakit Hal ini kemungkinan disebabkan oleh seringnya mereka mendapat paparan pengetahuan tentang hipertensi. Dalampengelolaan penyakithipertensi persepsi terhadap penyakit merupakan salah satu aspek penting penatalaksanaan disampng pengobatan dan self care management. Karena bagaimanapun juga persepsi akan mempengaruhi seseorang dalam pengambilan keputusan yang akan dibuatnya termasuk dalam hal pengelolaan penyakit. Hal ini diperkuat oleh hasil penelitian Shakya, et.al bahwa ada kolerasi antara persepsi dengan kepatuhan penderita dalam melakukan pengobatan Penelitian lainnya melaporkan bahwa persepsi penyakit berhubungan juga dengan kualitas hidup penderita.(Pratiwi, Untari, \& Robiyanto, 2020; Shakya et al., 2020). Oleh karena itu meningkatkan persepsi yang positif penderita menjadi penting dilakukan oleh petugas kesehatan.

\section{SIMPULAN DAN SARAN}

Berdasarkan hasil penelitian ditemukan tiga tema dalam penelitian ini yaitu kepatuhan dan pengobatan yang dilakukan, upaya self care management, dan persepsi terhadap penyakit. Terkait tema kepatuhan dan pengobatan yang dilakukan diketahui adanya ungkapan partisipan mengenai pemakaian obat hipertensi yang terus menerus akan berdampak pada organ lain. Persepsi ini memengaruhi kepatuhan pengobatan partisipan. Dengan demikian, disarankan kepada petugas kesehatan agar memberikan intervensi yaitu pendidikan kesehatan yang tepat kepada penderita hipertensi terutama tentang kepatuhan dan efek samping obat.

\section{DAFTAR PUSTAKA}

Ashoorkhani, M., Majdzadeh, R., Gholami, J., Eftekhar, H., \& Bozorgi, A. (2018). Understanding non-adherence to treatment in hypertension: A qualitative study. International Journal of Community Based Nursing and Midwifery, 6(4), 314-323. https://doi. org/10.30476/ijcbnm.2018.40838

Atmarita, A., Jahari, A. B., Sudikno, S., \& Soekatri, M. (2017). ASUPAN GULA, GARAM, DAN LEMAK DI INDONESIA: Analisis Survei Konsumsi Makanan Individu (SKMI) 2014. Gizi Indonesia, 39(1), 1. https://doi. org/10.36457/gizindo.v39i1.201

Bairami, S., Fathi, Y., Mohammadinasab, S., Barati, M., \& Mohammadi, Y. (2017). Relationship between Self-care Behaviors and Quality of Life among Hypertensive Patients Visiting Comprehensive Health Centers in Hamadan, Iran. Journal of Education and Community Health, 4(1), 20-27. https://doi.org/10.21859/ jech.4.1.20 
Diskominfo - PPID. (2017). enyakit Tidak Menular Tinggi, Kota Bandung Kampanyekan Hidup SehatNo Title. Retrieved from https://ppid.bandung. go.id/penyakit-tidak-menular-tinggikota-bandung-kampanyekan-hidupsehat/

He, F. J., Li, J., \& Macgregor, G. A. (2013). Effect of longer-term modest salt reduction on blood pressure. Cochrane Database of Systematic Reviews, 2013(4). https://doi. org/10.1002/14651858.CD004937.pub2

John Edward Hall, A. C. G. (2014). Guyton dan Hall buku ajar fisiologi kedokteran. Elsevier.

Kemenkes RI. (2019). Hipertensi Si Pembunuh Senyap. Kementrian Kesehatan RI, 1-5. Retrieved from https://pusdatin. kemkes.go.id/resources/download/ pusdatin/infodatin/infodatin-hipertensisi-pembunuh-senyap.pdf

Khomaini, A., Setiati, S., Lydia, A., \& Dewiasty, E. (2017). Pengaruh Edukasi Terstruktur dan Kepatuhan Minum Obat Antihipertensi terhadap Penurunan Tekanan Darah Pasien Hipertensi Usia Lanjut: Uji Klinis Acak Tersamar Ganda. Jurnal Penyakit Dalam Indonesia, 4(1), 4. https://doi.org/10.7454/jpdi.v4i1.106

Laelasari, E., Prasodjo, R. S., Cahyorini, C., Handayani, K., Wiryawan, Y., \& Anwar, A. (2019). Model Intervensi Hipertensi Di Puskesmas Purwoyoso, Semarang. Jurnal Ekologi Kesehatan, 18(1), 15-26. https:// doi.org/10.22435/jek.18.1.1472.15-26

Maryam, S. (2017). Strategi Coping: Teori Dan Sumberdayanya. JURKAM: Jurnal Konseling Andi Matappa, 1(2), 101. https://doi.org/10.31100/jurkam.v1i2.12

Peltzer, K., \& Pengpid, S. (2018). The Prevalence and Social Determinants of Hypertension among Adults in Indonesia:
A Cross-Sectional Population-Based National Survey. International Journal of Hypertension, 2018. https://doi. org/10.1155/2018/5610725

Pratiwi, N. P., Untari, E. K., \& Robiyanto, R. (2020). Hubungan Persepsi dengan Kualitas Hidup Pasien Hipertensi Lanjut Usia di RSUD Sultan Syarif Mohamad Alkadrie Pontianak. JURNAL MANAJEMEN DAN PELAYANAN FARMASI (Journal of Management and Pharmacy Practice), 10(2), 118. https:// doi.org/10.22146/jmpf.45579

Salami, S., \& Wilandika, A. (2018). Volume 5 | Nomor 2 | Desember 2018. Jurnal Keperawatan, 5(6), 99-106. Retrieved from https://scholar.google.co.id/citation s? user $=$ FPUjHVYAAAAJ $\& \mathrm{hl}=\mathrm{id} \# \mathrm{~d}=\mathrm{gs}$ md_cita-d $\& u=\% 2$ Fcitations $\% 3$ Fview op $\% 3$ Dview_citation $\% 26 \mathrm{hl} \% 3 \mathrm{Did} \% 26 \mathrm{u}$ ser\%3DFPUjHVYAAAAJ\%26c

Shakya, R., Shrestha, S., Gautam, R., Rai, L., Maharjan, S., Satyal, G. K., ... Rai, M. K. (2020). Perceived illness and treatment adherence to hypertension among patients attending a tertiary hospital in Kathmandu, Nepal. Patient Preference and Adherence, 14, 2287-2300. https:// doi.org/10.2147/PPA.S270786

Tucker, K. L., Sheppard, J. P., Stevens, R., Bosworth, H. B., Bove, A., Bray, E. P., ... McManus, R. J. (2017). Self-monitoring of blood pressure in hypertension: A systematic review and individual patient data meta-analysis. PLoS Medicine, 14(9), 1-29. https://doi.org/10.1371/ journal.pmed.1002389

Unger, T., Borghi, C., Charchar, F., Khan, N. A., Poulter, N. R., Prabhakaran, D., ... Schutte, A. E. (2020). 2020 International Society of Hypertension Global Hypertension Practice Guidelines. Hypertension, 75(6), 
1334-1357. https://doi.org/10.1161/ HYPERTENSIONAHA.120.15026

World Health Day. (2013). A global brief on Hyper tension World Health Day 2013. World Health Organization, 1-40.

World Health Organization.(2017a).Low-salt diet for patients with hypertension. Retrieved from http://apps.who.int/iris/bitstream/ handle/10665/254746/9789290618003$\mathrm{h}$ y $\mathrm{p}-\mathrm{m}$ o d 4 - e $\mathrm{n}$ g . pdf? sequence $=4 \&$ isAllowed $=y$

World Health Organization. (2017b). Physical activity for patients with hypertension. Noncommunicable Disease Education Manual for Primary Health Care Professionals and Patients, 1-25. 
